\title{
PPAR $\gamma$ insufficiency enhances osteogenesis through osteoblast formation from bone marrow progenitors
}

\author{
Toru Akune,, ${ }^{1}$ Shinsuke Ohba, ${ }^{2}$ Satoru Kamekura, ${ }^{1}$ Masayuki Yamaguchi, ${ }^{1}$ Ung-il Chung, ${ }^{2}$ \\ Naoto Kubota, ${ }^{3}$ Yasuo Terauchi, ${ }^{3}$ Yoshifumi Harada, ${ }^{4}$ Yoshiaki Azuma, ${ }^{4}$ Kozo Nakamura, ${ }^{1}$ \\ Takashi Kadowaki, ${ }^{3}$ and Hiroshi Kawaguchi ${ }^{1}$ \\ ${ }^{1}$ Department of Orthopaedic Surgery, ${ }^{2}$ Department of Tissue Engineering, and ${ }^{3}$ Department of Metabolic Diseases, Faculty of Medicine, \\ University of Tokyo, Tokyo, Japan. ${ }^{4}$ Teijin Co., Tokyo, Japan.
}

\begin{abstract}
Based on the fact that aging is associated with a reciprocal decrease of osteogenesis and an increase of adipogenesis in bone marrow and that osteoblasts and adipocytes share a common progenitor, this study investigated the role of PPAR $\gamma$, a key regulator of adipocyte differentiation, in bone metabolism. Homozygous $P P A R \gamma$-deficient ES cells failed to differentiate into adipocytes, but spontaneously differentiated into osteoblasts, and these were restored by reintroduction of the PPAR $\gamma$ gene. Heterozygous PPAR $\gamma$-deficient mice exhibited high bone mass with increased osteoblastogenesis, but normal osteoblast and osteoclast functions, and this effect was not mediated by insulin or leptin. The osteogenic effect of PPAR $\gamma$ haploinsufficiency became prominent with aging but was not changed upon ovariectomy. The PPAR $\gamma$ haploinsufficiency was confirmed to enhance osteoblastogenesis in the bone marrow cell culture but did not affect the cultures of differentiated osteoblasts or osteoclast-lineage cells. This study demonstrates a PPAR $\gamma$ dependent regulation of bone metabolism in vivo, in that PPAR $\gamma$ insufficiency increases bone mass by stimulating osteoblastogenesis from bone marrow progenitors.
\end{abstract}

\section{Introduction}

Osteoblasts and adipocytes share a common progenitor: multipotential mesenchymal stem cells in bone marrow (1-3). Accumulated evidence of the differentiation switching of these two cell lineages suggests that a large degree of plasticity exists between them and that the relationship is reciprocal (4-6). The clinical fact that a decrease in bone volume (BV) of age-related osteoporosis is accompanied by an increase in marrow adipose tissue (7-9) also implies the possible reciprocal relationship that is postulated to exist between the two differentiation pathways. The signal transduction pathways implicated in this process are therefore evaluated as potential targets for therapeutic intervention of osteoporosis. The molecular mechanism underlying the reciprocal relationship is not yet well understood, however, although several studies using strain-specific and $\mathrm{KO}$ murine models have begun to explore the relationship in vivo (10-15).

Several key transcription factors that function in the complex transcriptional cascade during adipocyte differentiation have been identified, including PPAR $\gamma$ and CCAAT enhancer-binding proteins (C/EBPs) (16). PPAR $\gamma$ is a ligand-activated transcription factor that belongs to the nuclear hormone receptor superfamily and functions as a heterodimer with a retinoid $X$ receptor by binding to the PPAR responsive element (PPRE) within the promoters of the target genes

Nonstandard abbreviations used: alkaline phosphatase (ALP); bone morphogenetic protein-2 (BMP-2); bone volume (BV); CCAAT enhancer-binding proteins (C/EBPs); computed tomography (CT); LDL receptor-related protein 5 (LRP5); leukemia inhibitory factor (LIF); M-CSF-dependent bone marrow macrophage (M-BMM $\phi)$; receptor activator of nuclear factor $\mathrm{\kappa B}$ ligand (RANKL); ovariectomy (OVX); PPAR responsive element (PPRE); tartrate-resistant acid phosphatase (TRAP); tissue volume (TV); type I collagen $\alpha 1$ chain (COL1A1).

Conflict of interest: The authors have declared that no conflict of interest exists. Citation for this article: J. Clin. Invest. 113:846-855 (2004). doi:10.1172/JCI200419900.
(17-19). PPAR $\gamma$ is expressed early in the adipocyte differentiation program and is activated by long-chain fatty acids, peroxisome proliferators, and the thiazolidinedione class of antidiabetic agents (17-19). Most importantly, PPAR $\gamma$ plays requisite and sufficient roles in the regulation of adipocyte differentiation, because its overexpression in fibroblast cell lines initiates adipogenesis (20) and ES cells and embryonic fibroblastic cells from mice lacking $P P A R \gamma$ were unable to differentiate into adipocytes (21-23).

When one takes the results of the studies together, it is possible that PPAR $\gamma$ may contribute not only to adipogenesis, but also to osteogenesis in the bone marrow where bipotential precursors can differentiate to either adipocytes or osteoblasts. This study investigated the physiological role of PPAR $\gamma$ on the marrow cells and bone cells using in vivo morphological analyses and ex vivo cell culture systems. For the in vivo analysis, we used mice lacking the PPAR $\gamma$ gene, which we generated by gene targeting (22). Although the homozygous PPAR $\gamma$ deficient $\left(P P A R \gamma^{-}\right)$mice were embryonically lethal at 10.5-11.5 days after post coitum due to placental dysfunction, heterozygous $P P A R \gamma-$ deficient $\left(P P A R \gamma^{+-}\right)$mice developed normally. The heterozygotes led to a $50 \%$ reduction in PPAR $\gamma$ expression and exhibited resistance to high-fat diet-induced obesity and insulin resistance; however, on a standard diet they grew normally, without abnormalities in major organs such as brain, heart, liver, spleen, or kidney $(22,24)$. We show here that the homozygous PPAR $\gamma$-deficient ES cells spontaneously differentiate into osteoblasts ex vivo and that PPAR $\gamma$ haploinsufficiency due to the heterozygous PPAR $\gamma$ deficiency resulted in enhanced bone formation with increased osteoblastogenesis from bone marrow progenitors both in vivo and ex vivo.

\section{Methods}

Animals. The generation of PPAR $\gamma$ gene-targeted mice was described previously (22). In each experiment, WT and $P P A R \gamma^{+/}$ 
mice littermates fed a standard diet were compared. All experiments were performed on male mice at 8 or 52 weeks of age, except for the ovariectomy (OVX) experiment in which female mice underwent surgical operation at 26 weeks and were analyzed at 30 weeks. All experiments were performed according to the protocol approved by the Animal Care and Use Committee of the University of Tokyo.

ES cell cultures. Mouse PPAR $\gamma^{/-}$and WT ES cells were isolated from blastocysts generated by mating $P P A R \gamma^{+/-}$mice with each other, as previously described (25). ES cells were maintained in DMEM medium supplemented with 15\% FBS, $200 \mathrm{mM} \mathrm{L-glu-}$ tamine, $100 \mu \mathrm{M} \beta$-mercaptoethanol, and $10^{3} \mathrm{U} / \mathrm{ml}$ of leukemia inhibitory factor (LIF; Chemicon International, Temecula, California, USA). Differentiation of ES cells was induced by using a modified protocol, described previously $(2,26)$. In brief, after being trypsinized with $0.025 \%$ trypsin-EDTA, cells were plated onto a bacterial Petri dish in the absence of LIF and cultured with $100 \mathrm{nM}$ all-trans retinoic acid for 5 days, with medium being replenished on day 3 . The embryoid bodies were transferred to a gelatinized six-multiwell plate and allowed to adhere to the well with DMEM containing 10\% FBS. For the analysis of osteogenic differentiation, cultures were maintained in the same condition without any additional supplements for 10 days, were fixed with $10 \%$ buffered formalin, and were incubated in the presence of $5 \%$ silver nitrate solution under an ultraviolet light for 10 minutes, then incubated for 5 minutes in the presence of 5\% sodium thiosulfate solution (von Kossa staining). To discern the calcified nodules from the embryoid body, both of which are seen as black, the von Kossa-positive nodules that do not connect to the embryoid body in a well were counted. For the analysis of adipogenesis, the medium was supplemented with $1 \mu \mathrm{M}$ troglitazone (Sankyo Pharmaceutical Co., Tokyo, Japan) for 10 days, fixed in $10 \mathrm{mM}$ sodium periodate, $2 \%$ paraformaldehyde, $75 \mathrm{mM}$ L-lysin dihydrochloride, and $37.5 \mathrm{mM}$ sodium phosphate, and then stained in a filtered solution of $0.3 \%$ oil red $\mathrm{O}$ in $60 \%$ isopropanol for 15 minutes. The red-stained, lipid vacuole-containing cells in a well were counted. To rescue osteoblast and adipocyte differentiation of $P P A R \gamma^{/-}$ES cells, the recombinant retrovirus vector carrying the PPAR $\gamma$ gene and empty vector were constructed as previously described (22). ES cells were infected with equal titers of each recombinant virus as described (20), with some modification.

Skeletal morphology and blood chemistry. A bone radiograph was taken with a soft x-ray apparatus (SOFTEX; CMB-2, Tokyo, Japan). A three-dimensional CT scan was taken using a composite $\mathrm{x}$-ray analyzing system (NX-HCP; NS-ELEX Inc., Tokyo, Japan) and the trabecular bone area (percentage of BV per tissue volume [TV]) was measured on the computed tomography (CT) image. All histological analyses were carried out using WT and $P P A R \gamma^{\dagger /-}$ littermates as previously described (27). Parameters for the trabecular bone and the number of bone marrow adipocytes was measured in an area $1.2 \mathrm{~mm}$ in length from $0.5 \mathrm{~mm}$ below the growth plate at the proximal metaphysis of the tibiae. The number of adipocytes in this area was determined by counting that of oval vacuoles in the toluidine blue staining. The thickness of the growth plate was measured at the proximal tibiae. Serum insulin was measured by insulin immunoassay (Morinaga Institute of Biological Science, Yokohama, Japan), and leptin was assayed with the ELISA-based Quantikine M mouse leptin immunoassay kit (R\&D Systems Inc., Minneapolis, Minnesota, USA).

Primary bone marrow cell cultures. Bone marrow cells were collected from long bones of 8-week-old PPAR $\gamma^{+/-}$and WT male lit- termates. Cells were plated at a density of $10^{6}$ cells on a six-multiwell plate in $\alpha$-MEM containing $10 \%$ FBS, with $1 \mu \mathrm{M}$ troglitazone for the adipogenesis assay and with $50 \mu \mathrm{g} / \mathrm{ml}$ ascorbic acid and 10 $\mathrm{mM} \beta$-glycerophosphate for osteogenesis assay. The oil red $\mathrm{O}$ staining was performed as mentioned above at 14 days of culture. For the alkaline phosphatase (ALP), cultured plates were rinsed with PBS, fixed in $100 \%$ ethanol at 10 days of culture, and stained with Tris-HCl-buffered solution ( $\mathrm{pH} 9.0$ ) containing naphthol AS-MX phosphate as a substrate and Fast Blue BB salt (SigmaAldrich, St. Louis, Missouri, USA) as a coupler. For the Alizarin red S staining, cultured plates were rinsed with PBS at 21 days of culture, fixed in $10 \%$ buffered formalin, and stained with $2 \%$ Alizarin red S ( $\mathrm{pH} 4.0$ ) (Sigma-Aldrich). The von Kossa staining was performed as mentioned above at 28 days of culture. For the growth curve assay, bone marrow cells derived from either WT or PPAR $\gamma^{+/}$littermates were inoculated at a density of $10^{7}$ cells per dish in $10-\mathrm{cm}$ culture dishes in $\alpha$-MEM containing $10 \%$ FBS, 50 $\mu \mathrm{g} / \mathrm{ml}$ ascorbic acid, and $10 \mathrm{mM} \beta$-glycerophosphate, and then was cultured for 3 days. The adherent cells were then harvested and inoculated at a density of $3 \times 10^{5}$ cells/dish in $10-\mathrm{cm}$ culture dishes and further cultured in the same medium. The number of cells per dish was counted 1, 2, 3, and 4 days after the seeding.

Real-time quantitative RT-PCR. Total RNA was extracted with an ISOGEN kit (Wako Pure Chemicals Industry Ltd., Osaka, Japan), according to the manufacturer's instructions, from ES cells cultured for 10 days after the embryoid bodies were transferred to gelatinized plates and from bone marrow cells cultured for 14 days after the seeding. One microgram of RNA was reverse-transcribed using a Takara RNA PCR Kit (AMV) ver. 2.1 (Takara Shuzo Co., Shiga, Japan) to make single-stranded cDNA. PCR was performed on an ABI Prism 7000 Sequence Detection System (Applied Biosystems Inc., Foster City, California, USA). The PCR reactions consisted of QuantiTect SYBR Green PCR Master Mix (QIAGEN, Tokyo, Japan), $0.3 \mu \mathrm{M}$ specific primers, and $500 \mathrm{ng}$ of cDNA. Relative levels of mRNA of a specific gene were calculated using the standard curve generated with cDNA dilutions, with normalization to actin as an internal control. PCR primers of specific genes used for amplification are available upon request.

Primary osteoblastic cell cultures. Osteoblastic cells were isolated from calvariae of neonatal WT and $P P A R \gamma^{\dagger /}$ littermates as previously described (27). For the cell proliferation assay, cells were inoculated at a density of $10^{4}$ cells/well in a 24-multiwell plate, cultured in the same medium for 48 hours, and deprived of serum for 12 hours before adding the experimental medium with and without troglitazone $(1 \mu \mathrm{M})$ or FGF-2 (1 nM; Kaken Pharmaceutical Co., Chiba, Japan). Incorporation of $\left[{ }^{3} \mathrm{H}\right]$-thymidine $(1 \mu \mathrm{Ci} / \mathrm{ml}$ in the medium $)$ added for the final 3 hours was measured after 24 hours of culture. For ALP activity measurement, cells were inoculated at a density of $10^{4}$ cells/well in a 24-multiwell plate and cultured in $\alpha$-MEM containing $10 \% \mathrm{FBS}$ and $50 \mu \mathrm{g} / \mathrm{ml}$ ascorbic acid with and without troglitazone $(1 \mu \mathrm{M})$ or bone morphogenetic protein-2 (BMP-2; $30 \mathrm{ng} / \mathrm{ml}$; Yamanouchi Pharmaceutical Co., Tokyo, Japan). At 14 days of culture, cells were sonicated in $10 \mathrm{mM}$ Tris- $\mathrm{HCl}$ buffer ( $\mathrm{pH}$ 8.0) containing $1 \mathrm{mM} \mathrm{MgCl}_{2}$ and $0.5 \%$ Triton X-100. ALP activity in the lysate was measured using a Wako ALP kit (Wako Pure Chemicals Industry Ltd.), and the protein content was determined using a BCA protein assay reagent (Pierce Chemical Co., Rockford, Illinois, USA). For Alizarin red $\mathrm{S}$ and von Kossa stainings, cells were inoculated at a density of $5 \times 10^{4}$ cells/well in a six-multiwell plate in $\alpha$-MEM containing $10 \% \mathrm{FBS}, 50 \mu \mathrm{g} / \mathrm{ml}$ ascorbic acid, and $10 \mathrm{mM} \beta$-glyc- 
erophosphate, and were stained at day 21 and 28, respectively, as mentioned above. Difference in maturity between the bone marrow cells and the calvarial osteoblasts was examined by the calcified nodule formation determined by Alizarin red S staining and the osteocalcin expression determined by real-time PCR analysis.

Assays for osteoclastic cells. Tartrate-resistant acid phosphatasepositive (TRAP-positive) multinucleated osteoclasts were generated by coculturing osteoblastic cells $\left(10^{4}\right.$ cells/well) and bone marrow cells $\left(5 \times 10^{5}\right.$ cells/well $)$ derived from either WT or PPAR $\gamma^{+/}$littermates, as mentioned above, in a 24-multiwell plate in $\alpha$-MEM containing $10 \%$ FBS for 6 days with and without $1,25(\mathrm{OH})_{2} \mathrm{D}_{3}(10 \mathrm{nM})$, prostaglandin $\mathrm{E}_{2}(100 \mathrm{nM})$, and IL-11 $(10 \mathrm{ng} / \mathrm{ml})$. Cells positively stained for TRAP containing more than three nuclei were counted as osteoclasts. To determine bone resorption activity, osteoclasts formed by the coculture on $0.24 \%$ collagen gel coated on $100-\mathrm{mm}$ dishes were digested with $0.2 \%$ collagenase solution, and a 1:50 aliquot including osteoclasts was seeded on a dentine slice. After 48 hours of culture in $\alpha$-MEM containing $10 \%$ FBS, the total area of pits stained with $0.5 \%$ toluidine blue was evaluated using an image analyzer. To study the role of PPAR $\gamma$ intrinsic to osteoclastic cells, we used the M-CSF-dependent bone marrow macrophage (M-BMM $\phi$ ) culture system as described previously (28). Briefly, bone marrow cells from WT or PPAR $\gamma^{+/-}$mice were seeded at a density of $3 \times 10^{5}$ cells/well in a 24-multiwell plate and cultured in $\alpha$-MEM containing 10\% FBS with M-CSF (100 ng/ml). After culturing for 3 days, adherent cells (M-BMM $\phi)$ were further cultured with M-CSF (100 $\mathrm{ng} / \mathrm{ml})$ and soluble receptor activator of nuclear factor $\mathrm{\kappa B}$ ligand (RANKL) (100 ng/ml) for 3 days. TRAP-positive osteoclasts were counted. To determine the survival, osteoclasts generated as above were deprived of M-CSF/soluble RANKL and cultured for an additional 48 hours. At 3, 6, 12, 24, and 48 hours, the TRAP-positive and trypan blue-negative osteoclasts were counted.

Statistical analysis. Means of groups were compared by ANOVA, and significance of differences was determined by post-hoc testing using Bonferroni's method.

\section{Results}

Osteogenesis is enhanced in the homozygous PPAR $\gamma$-deficient ES cell culture. To examine the involvement of the PPAR $\gamma$ signaling in fat and bone metabolism, we first compared the adipogenesis and osteogenesis in
A
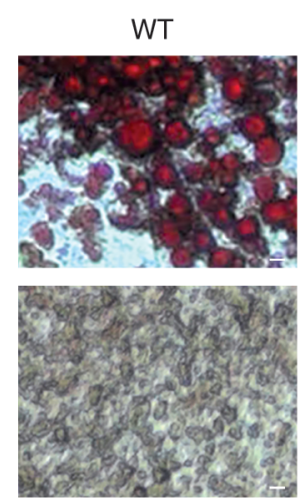
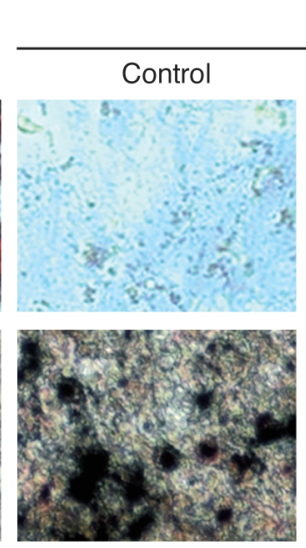

PPAR $\gamma^{\prime-}$

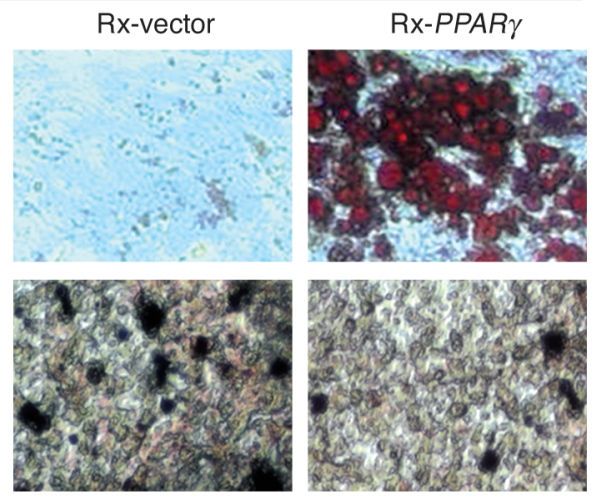

B
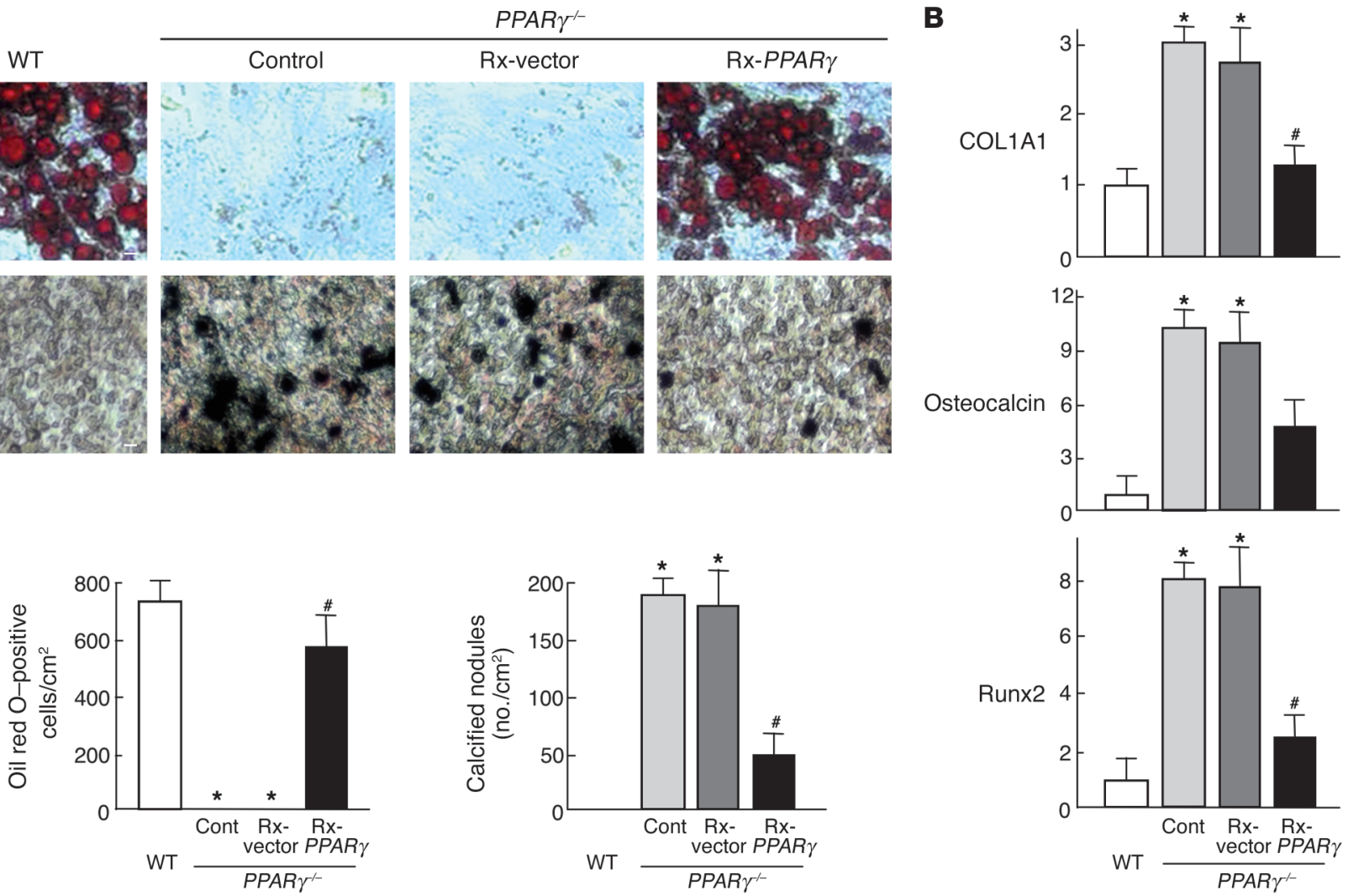

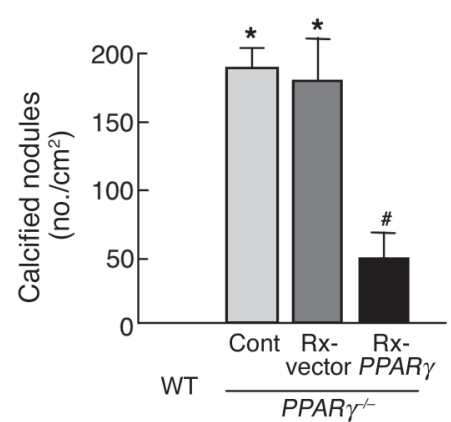

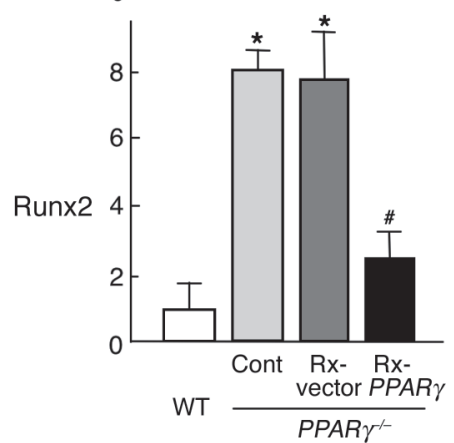

Figure 1

Adipogenesis and osteogenesis in the mouse ES cell cultures of homozygous PPAR $\gamma$-deficient $\left(P P A R \gamma^{\prime-}\right)$ and WT genotypes. As a rescue experiment, PPAR $\gamma$ was reintroduced into $P P A R \gamma^{\prime-}$ ES cells using a retrovirus vector carrying the PPAR $\gamma$ gene $(\mathrm{Rx}-P P A R \gamma)$ or the same retrovirus vector without the PPAR $\gamma$ gene (Rx-vector) as a control. (A) The upper row shows the adipogenesis determined by the oil red $\mathrm{O}$ staining of the ES cell culture in DMEM $/ 10 \%$ FBS with troglitazone. The number of oil red O-positive cells stained in red was counted and shown in the left graph as the cells per square centimeter. The images in the lower row indicate the osteogenesis determined by the von Kossa staining of the ES cell culture in DMEM/10\% FBS without any osteogenic supplements. The number of von Kossa-positive calcified nodules stained in black was counted and shown in the right graph as the number per square centimeter. Scale bar: $20 \mu \mathrm{m}$. (B) Relative mRNA levels of the marker genes for osteoblasts - COL1A1, osteocalcin and Runx2 - determined by real-time quantitative RT-PCR 10 days after the embryoid bodies were transferred to a gelatinized six-multiwell plate in DMEM/10\% FBS without any osteogenic supplements. The ordinate axis indicates the relative amount of mRNA as compared with that of WT. Data are expressed as means (bars) \pm SEMs (error bars) for eight wells per group. *Significant difference from the WT culture, $P<0.01$. \#Significant restoration by Rx-PPAR $\gamma$ as compared with the control $P P A R \gamma^{\prime-}$ and $P P A R \gamma^{\prime-}$ plus Rx-vector cultures; $P<0.01$. Cont, control. 
A

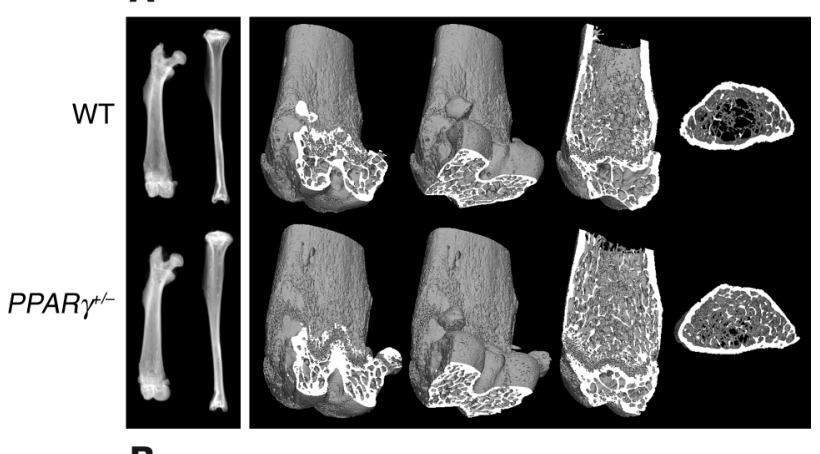

B
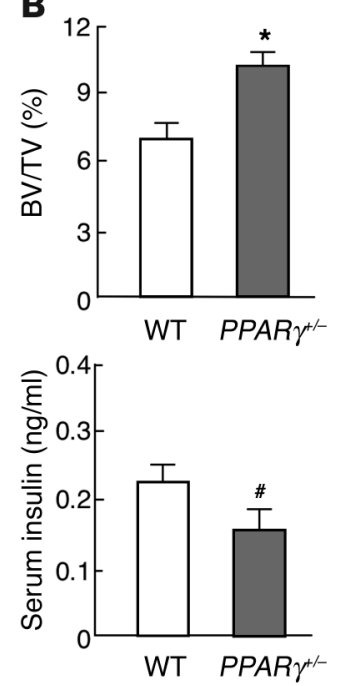
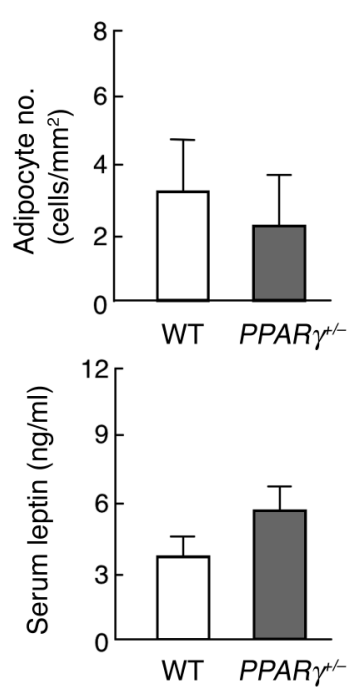
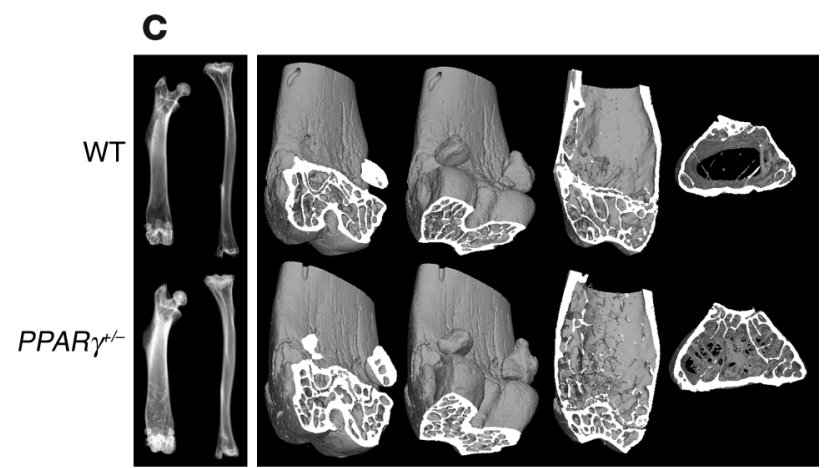

D
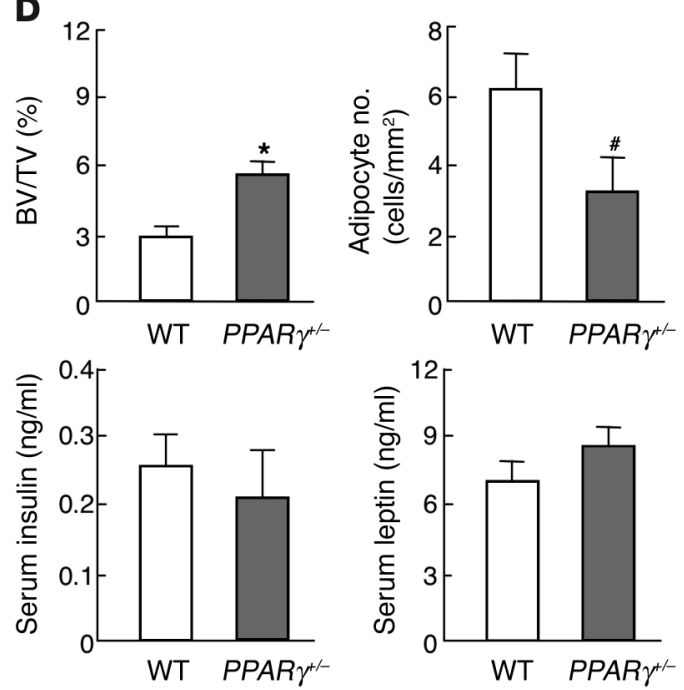

Figure 2

Radiological analysis and blood chemistry of heterozygous PPAR $\gamma$-deficient (PPAR $\left.\gamma^{+/-}\right)$and WT littermates at 8 weeks (A and B) and 52 weeks (C and D) of age. (A and C) Plain x-ray images of femora and tibiae (left) and three-dimensional CT images of distal femora (right) of representative PPAR $\gamma^{+-}$and WT littermates. (B and D) Trabecular BV expressed as percentage of total tissue volume (BV/TV [\%]) at the distal femora was measured on the CT image. The number of adipocytes in the bone marrow, measured histologically, is shown here for collation with the BV/TV data. Insulin and leptin levels in serum taken just before the sacrifice were quantified using immunoassay kits. Data are expressed as means (bars) \pm SEMs (error bars) for eight mice per group for $P P A R \gamma^{+-}$and WT mice. Significant difference from WT: ${ }^{*} P<0.01$, ${ }^{*} P<0.05$.

the cultures of ES cells between PPAR $\gamma^{\prime-}$ and WT (WT or PPAR $\gamma^{\prime /+}$ ) genotypes isolated from blastocysts generated by mating PPAR $\gamma^{1-}$ mice (Figure 1A). In the presence of troglitazone, a thiazolidinedione that is a potent ligand of PPAR $\gamma$, a substantial amount of oil red O-positive adipocytes was formed from WT ES cells, whereas adipogenesis was not seen in the PPAR $\gamma^{\text {/ }}$ ES cell culture (Figure 1A, upper row of photographs). To confirm the direct association between PPAR $\gamma$ and adipogenesis, PPAR $\gamma$ was reintroduced into $P P A R \gamma^{\prime-E S}$ cells using a retrovirus vector carrying the PPAR $\gamma$ gene $(\mathrm{Rx}-P P A R \gamma)$. Adipogenesis was restored to the level similar to that of WT culture, although introduction of the same retrovirus vector without the PPAR $\gamma$ gene (Rx-vector) did not affect it. We then examined the osteogenesis in the PPAR $\gamma^{-}$and WT ES cell cultures. Surprisingly, in DMEM $/ 10 \%$ FBS without osteogenic supplements such as dexamethasone, $\beta$-glycerophosphate, ascorbic acid, or BMP, the formation of von Kossa-positive bone nodules was potently induced in the PPAR $\gamma^{\prime-E S}$ cell culture, while this was not seen at all in the WT culture (Figure 1A, lower row of photographs). Quantitative analysis of the mRNA levels by the real-time RT-PCR method revealed that the marker genes for osteoblasts - type I collagen $\alpha 1$ chain (COL1A1), osteocalcin, and Runx2 - were upregulated in the

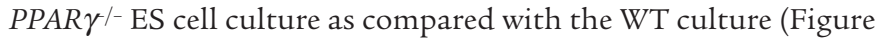
1B). Reintroduction of PPAR $\gamma$ into the PPAR $\gamma^{\prime-}$ culture by Rx-PPAR $\gamma$ significantly decreased the nodule formation and osteogenic marker gene expressions, while the control Rx-vector altered neither (Figure $1, \mathrm{~A}$ and $\mathrm{B})$. When one takes these results together, the observed mirror image regulations between adipogenesis and osteogenesis by loss and gain of the PPAR $\gamma$ function suggest a switching mechanism between the two differentiation pathways from common progenitors through the PPAR $\gamma$ signaling.

PPAR rhaploinsufficiency leads to high bone mass in vivo. To learn the effect of the PPAR $\gamma$ insufficiency in vivo, we analyzed the bones of $P P A R \gamma^{1-}$ mice because the homozygous deficient fetuses died too early for their skeletal analyses to be performed. PPAR $\gamma^{1-}$ mice showed normal weight gain without visible general lipodystrophy on a standard diet during the observation period of up to 52 weeks of age. The lengths of the trunk and long bones were also similar to those of WT littermates, indicating that PPAR $\gamma$ is not involved in the regulation of skeletal growth. X-ray and threedimensional CT analyses of femora and tibiae, however, revealed that PPAR $\gamma^{+/}$mice showed about $40 \%$ higher trabecular bone mass than WT littermates at 8 weeks of age (Figure 2, A and B). 
A

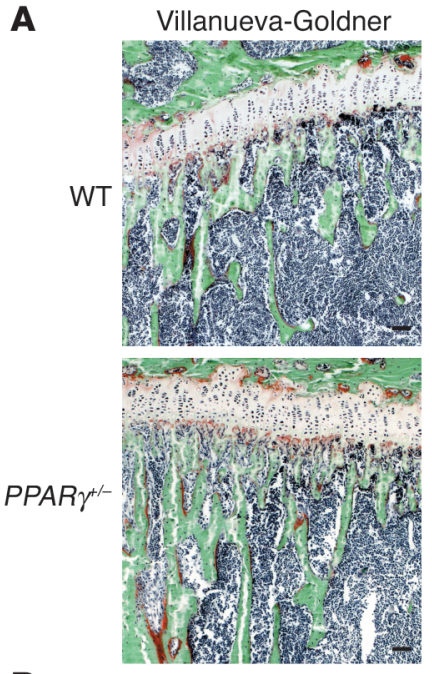

B

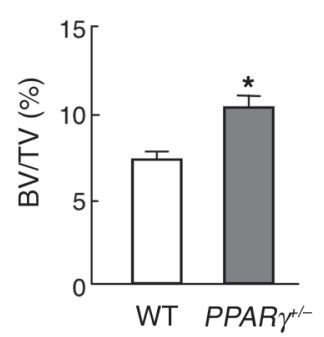

Calcein
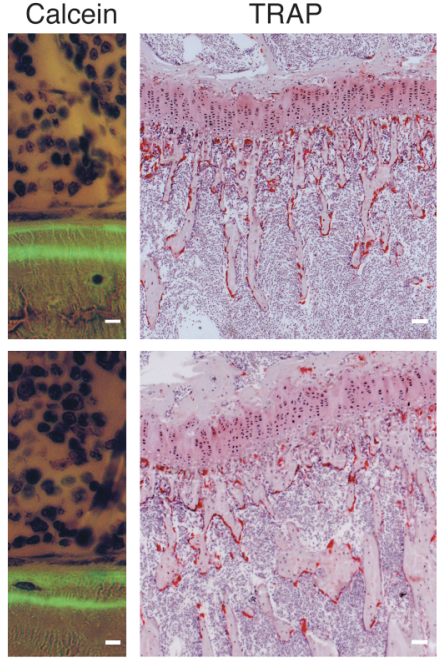

Toluidine blue

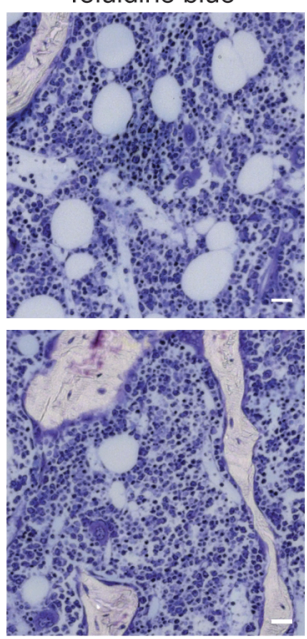

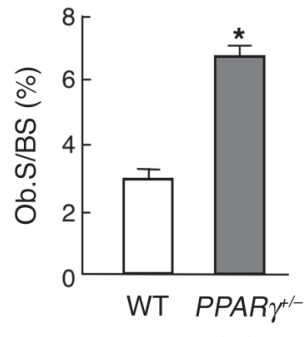

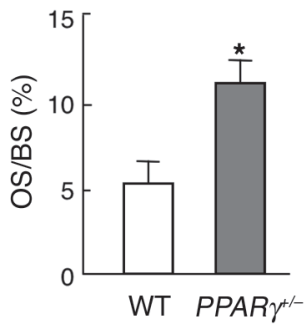

PPAR $\gamma^{+1 /}$
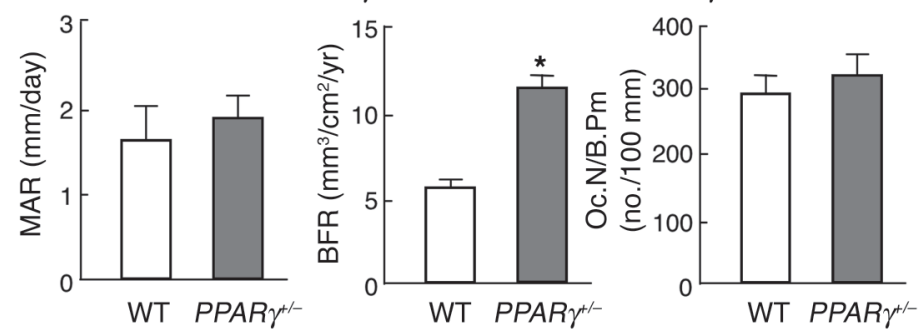

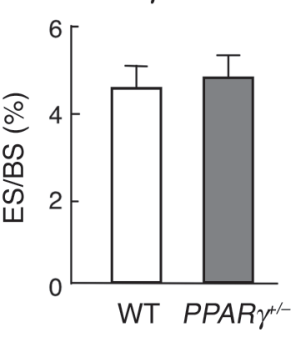

\section{Figure 3}

Histological analysis of the proximal tibiae of PPAR $\gamma^{+-}$and WT littermates. (A) Histological features at proximal tibiae of $P P A R \gamma^{+/}$and WT littermates. VillanuevaGoldner staining, calcein double labeling, and TRAP staining were done at 8 weeks; toluidine blue staining was done at 52 weeks of age. In Villanueva-Goldner staining, mineralized bone is stained green and unmineralized bone osteoid red; scale bar: $100 \mu \mathrm{m}$. In calcein double labeling, the mineralization front is stained as a green line; scale bar: $10 \mu \mathrm{m}$. In TRAP staining, TRAPpositive osteoclasts are stained red; scale bar: $100 \mu \mathrm{m}$. In toluidine blue staining, adipocytes are observed as oval vacuoles; scale bar: $50 \mu \mathrm{m}$. (B) Histomorphometric parameters at 8 weeks of age. Ob.S/BS, percentage of bone surface covered by cuboidal osteoblasts; OS/BS, percentage of bone surface covered by osteoid; MAR, mineral apposition rate; BFR, bone formation rate expressed by MAR times percentage of bone surface exhibiting double labels plus one-half single labels; Oc.N/B.Pm, number of mature osteoclasts in $100 \mathrm{~mm}$ of bone perimeter; ES/BS, percentage of eroded surface. Data are expressed as means (bars) \pm SEMs (error bars) for eight mice per group for $P P A R \gamma^{+/-}$and WT mice. *Significant difference from WT, $P<0.01$.
Contrarily, the number of adipocytes in the bone marrow determined as described below tended to be lower in the $P P A R \gamma^{+/-}$long bones compared with WT (Figure 2B). Similar changes of bone and fat were also seen in vertebral bodies (data not shown). To examine the involvement of systemic factors that are known to be related to bone and fat metabolism, the serum levels of insulin and leptin were compared between the two mouse genotypes. $P P A R \gamma^{+/}$mice showed lower, although not significantly lower, serum insulin level and higher leptin level than WT littermates as reported previously $(22,29)$. Since insulin is known to be osteogenic (30), whereas leptin is antiosteogenic $(11,13,31)$, neither of the changes in these hormones could explain the increased bone mass in PPAR $\gamma^{+/-}$mice.

Because age-related osteoporosis is known to be accompanied by reciprocal increase of bone marrow adipocytes (7-9), we further compared the bones of PPAR $\gamma^{\dagger-}$ and WT littermates at 52 weeks of age (Figure 2, C and D). The BV of femora and tibiae was decreased in both mouse genotypes at this age as compared with that at 8 weeks; however, the difference of BV between PPAR $\gamma^{+-}$and WT became more prominent at 52 weeks than at 8 weeks (95\% versus $40 \%$, respectively). The number of bone marrow adipocytes, which are shown as oval vacuoles by the toluidine blue staining (Figure 3A, right), was significantly decreased in $P P A R \gamma^{+-}$mice at this age. This tendency was similarly observed in vertebral bodies (data not shown). Both insulin and leptin levels at this old age showed patterns similar to those at 8 weeks, although significant differences between the genotypes were not seen.

PPAR $\gamma$ haploinsufficiency leads to osteoblastogenesis in vivo. We further performed histological analyses of the proximal tibiae of 8-weekold PPAR $\gamma^{+/-}$mice. Villanueva-Goldner staining indicated increases of trabecular bones stained in green and osteoid surface stained in red in PPAR $\gamma^{+/}$mice as compared with WT littermates; however, bone formation by individual osteoblasts determined by the calcein double labeling and the number of TRAP-positive osteoclasts was similar for the two groups (Figure 3A). Bone histomorphometric analyses (Figure 3B) confirmed the increase of BV by PPAR $\gamma$ haploinsufficiency to be about $40 \%$. Among bone formation parameters, osteoblast surface and osteoid surface, both representative of the number of osteoblasts, were more than double in $P P A R \gamma^{+/}$than in WT littermates, while the mineral apposition rate that reflects the bone formation ability of individual osteoblasts did not differ between them. Consequently, bone formation rate that is determined by the number and the function of osteoblasts became about twice that by PPAR $\gamma$ haploinsufficiency. Bone resorption parameters, osteoclast number, and eroded surface did not differ between $P P A R \gamma^{+/-}$and WT mice. Taking these histologi- 
A
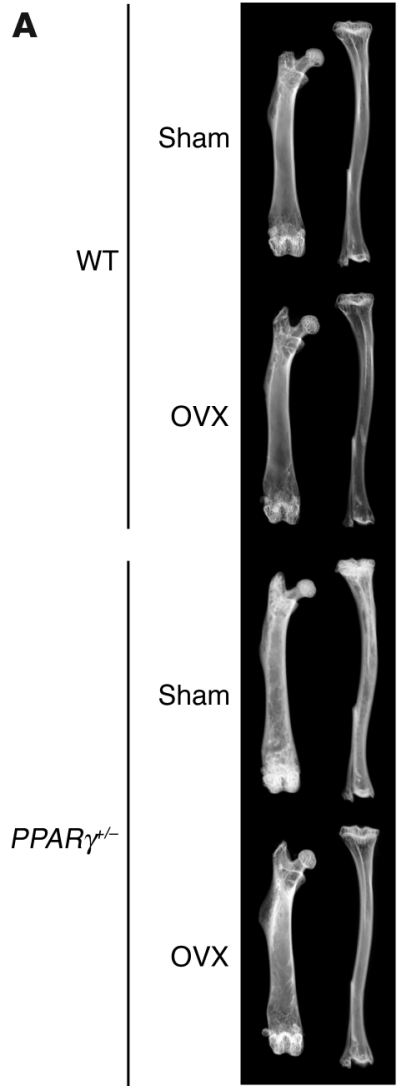

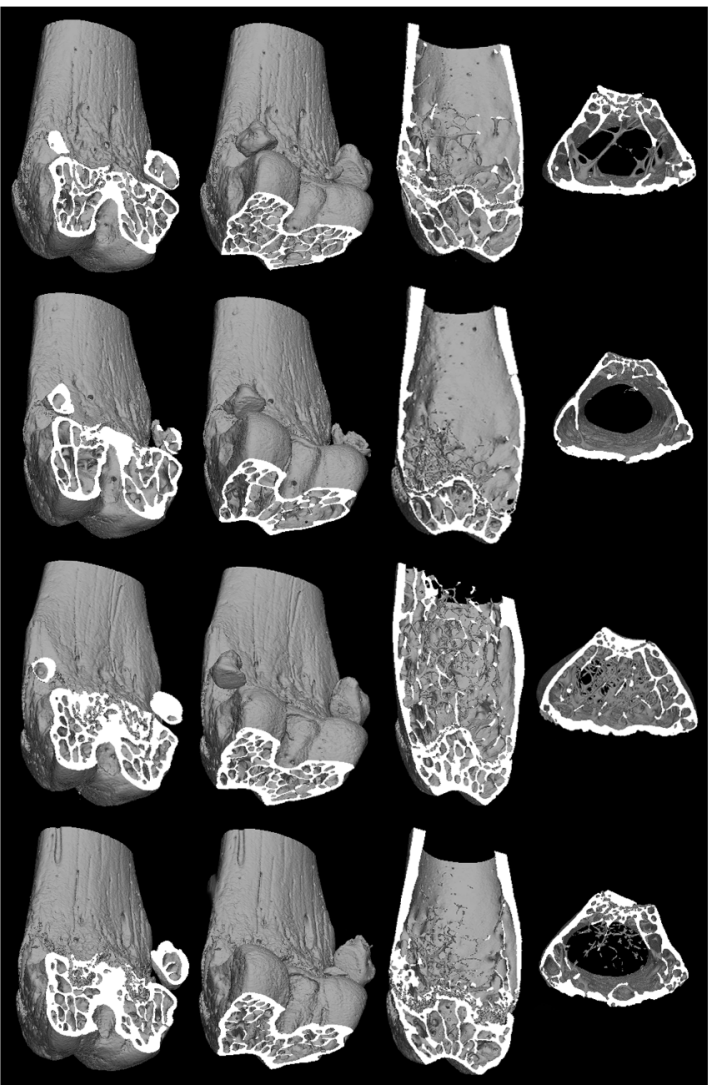

B
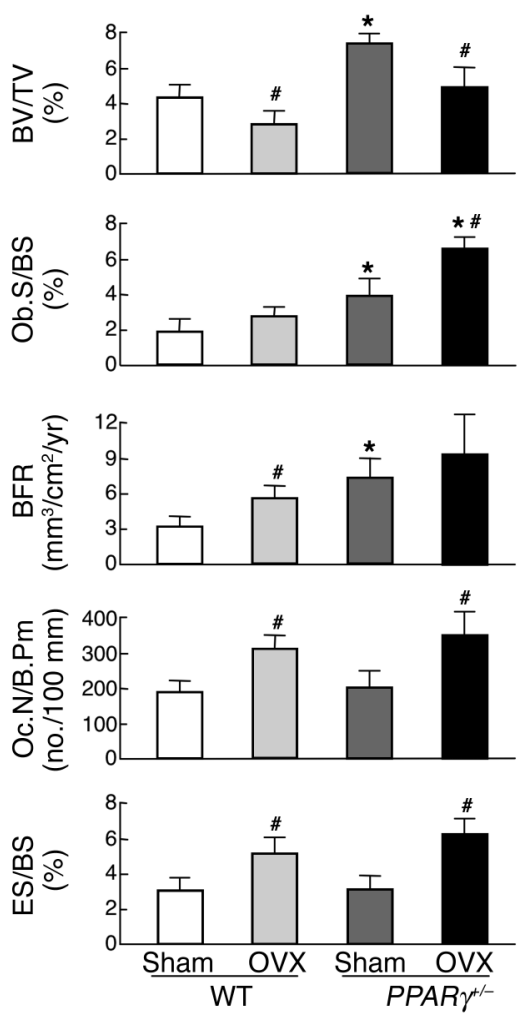

Figure 4

Radiological and histomorphometric analyses of OVX and sham-operated (Sham) female littermates of PPAR $\gamma^{+/-}$and WT genotypes. Female mice underwent surgical operation at 26 weeks and were analyzed at 30 weeks of age. (A) Plain x-ray images of femora and tibiae (left) and three-dimensional CT images of distal femora (right) of representative mice. (B) Histomorphometric parameters. Data are expressed as means (bars) \pm SEMs (error bars) for eight mice per group for $P P A R \gamma^{+-}$and WT mice. *Significant difference from WT, $P<0.01$. \#Significant difference from sham, $P<0.05$.

cal observations together, $P P A R \gamma^{+-}$mice exhibited high bone mass with increased osteoblastogenesis but normal osteoblast and osteoclast functions. The thickness of the growth plate at the proximal tibiae was not different between $P P A R \gamma^{+/-}$and WT littermates $(80.4 \pm 9.6$ and $82.7 \pm 10.3 \mu \mathrm{m}$, mean \pm SEM of eight mice each, respectively), confirming that PPAR $\gamma$ signaling is not important for bone growth through chondrocyte functions.

PPAR y haploinsufficiency does not affect bone loss by OVX. To investigate the involvement of the PPAR $\gamma$ signaling in the mechanism of bone loss by estrogen deficiency, OVX or sham operation was undertaken on 26-week-old female $P P A R \gamma^{\dagger /-}$ and WT littermates, and $\mathrm{BV}$ was compared 4 weeks after the operation. X-ray and threedimensional CT analyses of femora and tibiae suggested that both $P P A R \gamma^{+/}$and WT mice showed similar bone loss by OVX (Figure 4A). Histomorphometric analyses (Figure 4B) showed that BV was about $30 \%$ decreased by OVX in both PPAR $\gamma^{+/-}$and WT mice. These decreases were accompanied by increases in bone formation and bone resorption parameters, indicating a state of high bone turnover, in both genotypes. Hence, PPAR $\gamma$ haploinsufficiency did not affect the change of bone metabolism induced by OVX, suggesting that the PPAR $\gamma$ signaling does not contribute to osteopenia caused by estrogen deficiency.

PPAR $\gamma$ haploinsufficiency leads to osteoblastogenesis from cultured bone marrow cells. To investigate the cellular mechanism underlying the abnormality in the bone of $P P A R \gamma^{+/-}$mice, ex vivo cultures of bone marrow cells derived from long bones were performed. We first compared the cell proliferation determined by the growth curve for 4 days and found no difference between $P P A R \gamma^{\dagger /-}$ and WT marrow cells (Figure 5A). Adipogenesis from marrow cells in the presence of troglitazone was confirmed to be inhibited by PPAR $\gamma$ haploinsufficiency, however, since the number of oil red $\mathrm{O}$-positive adipocytes was decreased in the PPAR $\gamma^{\text {/- }}$ culture to about half that of the WT culture (Figure $5 \mathrm{~B}$ ). We further examined osteoblastogenesis in the bone marrow cell culture by comparing the numbers of colonies positively stained with ALP, Alizarin red S, and von Kossa (Figure 5C). All colonies were markedly increased in the $P P A R \gamma^{+/}$culture as compared with the WT culture, indicating the increase of osteoblastogenesis from bone marrow progenitors by PPAR $\gamma$ haploinsufficiency.

To further investigate the regulation of expression of genes related to bone metabolism by PPAR $\gamma$ haploinsufficiency, we compared mRNA levels of key or marker molecules for adipocyte and osteoblast differentiations between $P P A R \gamma^{+/}$and WT bone marrow cells (Figure 5D). As expected, PPAR $\gamma$ expression was reduced in the $P P A R \gamma^{\prime-}$ marrow cells compared with the WT. The levels of expression of other key factors for adipocyte differentiation, C/EBP- $\beta$ and $\mathrm{C} / \mathrm{EBP}-\delta$, in the PPAR $\gamma^{1-}$ marrow cells were comparable to those of WT, indicating that PPAR $\gamma$ was not essential for induction of these C/EBPs; contrarily, C/EBP- $\alpha$ was significantly reduced. Based on previous observations $(16,17,22,32,33)$ and these results, it appears that $\mathrm{C} / \mathrm{EBP}-\beta$ and $\mathrm{C} / \mathrm{EBP}-\delta$ lie upstream of PPAR $\gamma$, while $\mathrm{C} / \mathrm{EBP}-\alpha$ is 
A

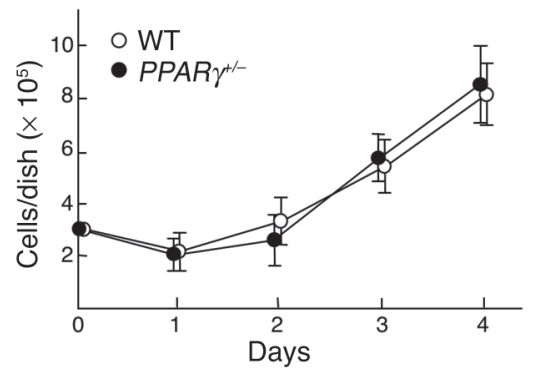

B
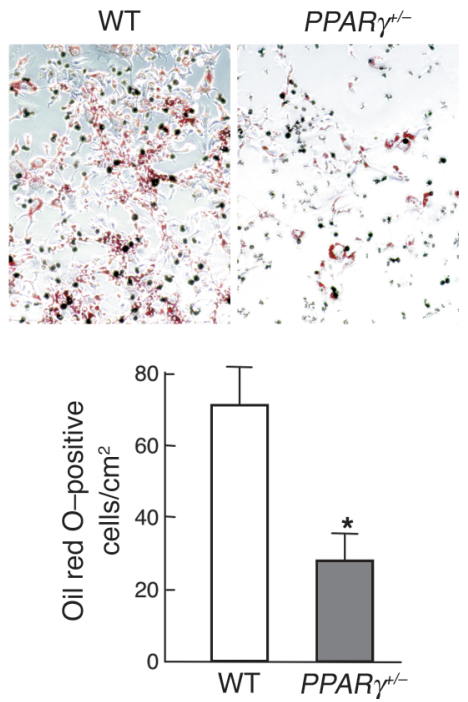
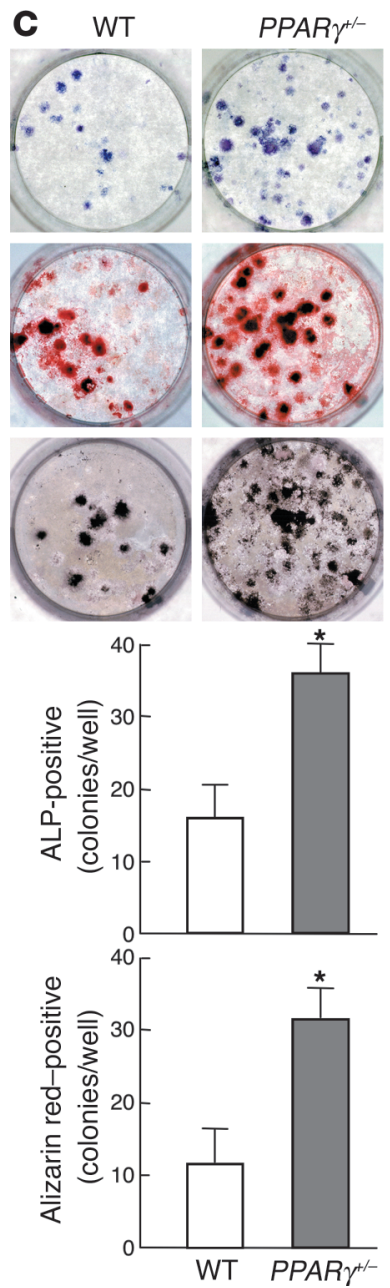

D
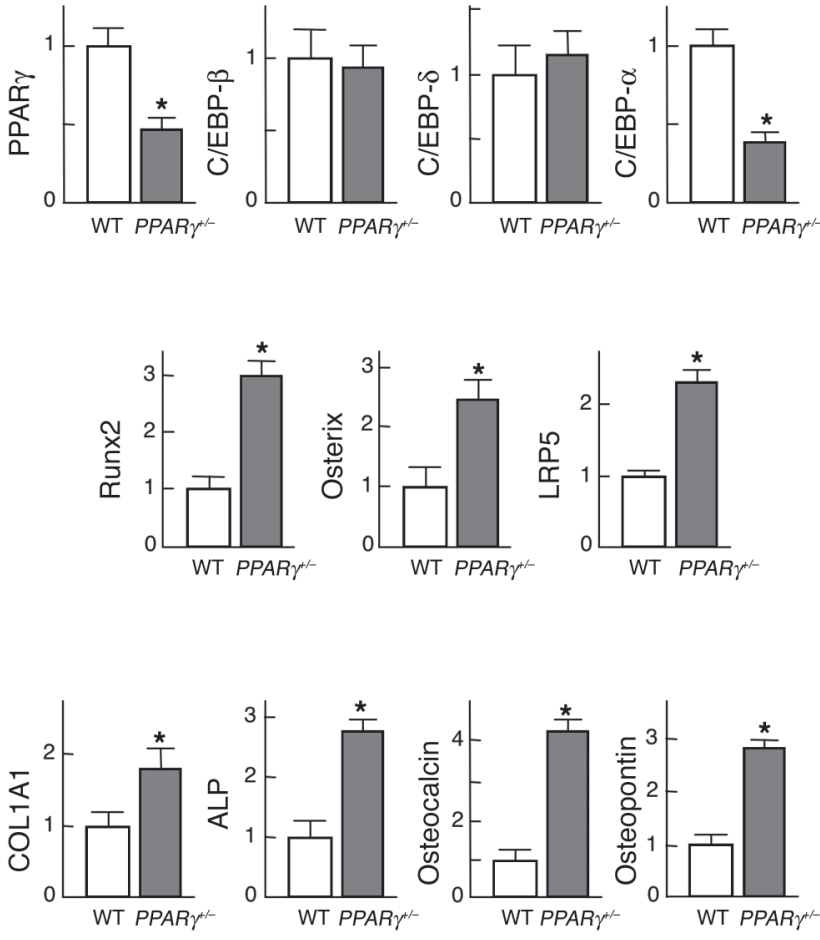

Figure 5

Adipogenesis and osteogenesis in the cultures of bone marrow cells from PPAR $\gamma^{+/-}$and WT littermates. (A) Growth curves of bone marrow cells isolated from PPAR $\gamma^{+/-}$and WT mice. The adherent bone marrow cells were inoculated at a density of $3 \times 10^{5} \mathrm{cells} / \mathrm{dish}$ in $10-\mathrm{cm}$ culture dishes. The cells per dish were counted at 1, 2, 3, and 4 days of culture. Data are expressed as means (symbols) \pm SEMs (error bars) for eight dishes per group. (B) Adipogenesis determined by oil red $\mathrm{O}$ staining in the culture of bone marrow cells in $\alpha-\mathrm{MEM} / 10 \%$ FBS with troglitazone. The graph indicates the number of positive cells per square centimeter. (C) Osteogenesis determined by ALP (upper row), Alizarin red (middle row), and von Kossa (lower row) stainings in the culture of bone marrow cells in $\alpha-M E M / 10 \%$ FBS with ascorbic acid and $\beta$-glycerophosphate. The graphs below indicate the number of ALP-positive (upper) and Alizarin red-positive (lower) colonies per well. Data are expressed as means (bars) \pm SEMs (error bars) for eight wells per group (B and C). *Significant difference from the WT culture, $P<0.01$. (D) Expression of key molecules for adipogenesis (PPAR $\gamma$, C/EBP- $\beta$, $\mathrm{C} / \mathrm{EBP}-\delta$, and C/EBP- $\alpha$ ) and osteogenesis (Runx2, osterix, and LRP5), and marker proteins for osteogenesis (COL1A1, ALP, osteocalcin, and osteopontin) determined by quantitative RT-PCR in the bone marrow cells at 14 days of culture under the conditions above. The ordinate axis indicates the relative amount of mRNA as compared with that of WT.

regulated, at least in part, downstream of PPAR $\gamma$. Regarding osteogenic factors, expressions of the putative central determinants of major pathways for osteoblast differentiation, Runx2 (34), osterix (35), and LDL receptor-related protein 5 (LRP5) (36), were increased in the PPAR $\gamma^{+-}$culture as compared with WT, indicating that the PPAR $\gamma$ signaling directly or indirectly impacts these major pathways for osteoblast differentiation. Expressions of matrix proteins representing osteogenesis, COL1A1, ALP, osteocalcin, and osteopontin, were also higher in the PPAR $\gamma^{+/-}$culture than in the WT culture, which was consistent with the in vivo histomorphometric data showing high bone mass with increased osteoblastogenesis.

When we examined the proliferation, differentiation, and matrix synthesis of cultured calvarial osteoblasts, which we confirmed to be more mature than bone marrow cells, none of them showed a difference between PPAR $\gamma^{+-}$and WT mice (data not shown). This indicates that PPAR $\gamma$ haploinsufficiency affects only marrow progenitors, but not cells that are more committed to osteoblastic lineage. Furthermore, studies using the coculture system of marrow cells/calvarial osteoblasts and the M-BMM $\phi$ culture system $(28,37)$ also failed to show difference of differentiation, bone-resorbing activity, or survival of the osteoclastic cells, suggesting that PPAR $\gamma$ is not important for osteoclast functions.

\section{Discussion}

Osteoblastogenesis was upregulated not only in the $P P A R \gamma^{+/-}$bone in vivo, but also in the cultures of PPAR $\gamma^{--}$ES cells and PPAR $\gamma^{+/-}$ 
primary bone marrow cells. Considering that the former culture was performed in the absence of any osteogenic stimulation, under which condition no WT stem cells can differentiate into osteoblasts, the intrinsic PPAR $\gamma$ signaling seems to function as a potent suppressor of commitment and differentiation to the osteoblastic lineage. Its molecular mechanism remains unclear, however. A previous report showed that a stable transfection of PPAR $\gamma$ and its activation with a thiazolidinedione-suppressed Runx2, type I collagen, and osteocalcin syntheses in the culture of a stromal cell line (38). Although the present study also showed that steady-state mRNA levels of the key molecules for osteoblast differentiation, Runx2, osterix, and LRP5, were upregulated in primary cultured marrow cells with PPAR $\gamma$ haploinsufficiency (Figure $5 \mathrm{D}$ ), whether this is transcriptional regulation or secondary to the increase in cells of osteoblast lineage in the culture is unknown. The predicted region of the PPAR $\gamma$-responsive element PPRE (TGACCTnTGACCT) has not been identified in the promoter of these genes and was not found by our genomic search, at least in the region between $4.0 \mathrm{~kb}$ upstream and $0.5 \mathrm{~kb}$ downstream of the transcriptional start point of runx2 (GenBank accession number NT 039655), osterix (NT 039621), and $\operatorname{lrp5}$ (NT 039684) genes. It should, however, also be noted that several reports have indicated that PPAR $\gamma$ regulates gene expression independently of PPRE, that is, by interfering with the function of AP-1, signal transducer and activator of transcription 1 (STAT1), and NF- $\mathrm{KB}$ (39), or by inhibiting the function of GHP-1, a transcription factor implicated in pituitary-specific gene expression (40). The AP-1 family members may possibly play a role in the mechanism, especially for mesenchymal cells. Activation of PPAR $\gamma$ is reported to suppress $c$-fos expression (41). Another AP-1 family member, DeltaFosB, is known to be a positive regulator of osteoblast differentiation, and the transgenic mouse leads to postnatal high bone mass with increased osteoblastogenesis and decreased adipogenesis in bone marrow (12). Another possible molecular mechanism is the interaction of PPAR $\gamma$ with the TGF- $\beta / \operatorname{Smad} 3$ signaling, which inhibits osteoblast differentiation $(42,43)$. Since Smad3 is reported to interact physically with Runx2 (42) and PPAR $\gamma(44)$, the interference by PPAR $\gamma$ with the Smad3 inhibition of Runx2 might be involved in the switching mechanism between adipocyte and osteoblast differentiation. The interaction of PPAR $\gamma$ with Wnt signaling might be another issue to pursue. The canonical Wnt pathway, likely mediated by Wnt $10 \mathrm{~b}$, is known to maintain preadipocytes in an undifferentiated state through stabilization of cytosolic $\beta$-catenin $(45,46)$. Since activation of PPAR $\gamma$ with troglitazone is not sufficient to repress expression of Wnt10b, Wnt signaling might lie upstream of PPAR $\gamma$. Recently, in addition to LRP5, which is a coreceptor of Wnt, the canonical Wnt-signaling molecules $\beta$-catenin and glycogen synthase kinase- $3 \beta$ have been reported to stimulate osteoblast differentiation $(47,48)$, indicating a switching between adipogenesis and osteogenesis by the Wnt signaling. Further studies on functional interaction of PPAR $\gamma$ with the transcriptional and signaling molecules above will elucidate the switching mechanism between the two differentiation pathways from common progenitors.

PPAR $\gamma$ may also inhibit osteogenesis indirectly through its stimulation of adipogenesis from marrow progenitors that can give rise to either osteoblasts or adipocytes. In fact, many experimental models have provided substantial evidence for this reciprocal relationship between cell lineages $(6,10-15)$, and there is little doubt that adipogenesis increases as BV decreases, suggesting that marrow adipogenesis has important implications in osteogenic disorders (7-9). Evidence of the transdifferentiation of stromal cells actually suggests a large degree of plasticity between osteoblasts and adipocytes $(4,49)$, although it is not clear at what point the phenotype of these multipotential cells becomes committed to either osteoblast or adipocyte differentiation. Since differentiated osteoblasts indicated by osteocalcin expression are reported to undergo adipogenic differentiation (4), it is possible that the reciprocal relationship between osteogenesis and adipogenesis may, at least in part, be due to the transdifferentiation between rather differentiated cells of the two lineages. To determine the role of PPAR $\gamma$ in more differentiated osteoblastic cells than bone marrow cells, we used calvarial cells whose spontaneous differentiation is known to follow not only the osteogenic pathway but also the adipogenic pathway (49). Despite the existence of PPAR $\gamma$ expression in these cells as well, its haploinsufficiency did not affect the cell functions, suggesting that PPAR $\gamma$ signaling may be involved in the earlier, but not the later, stage of relationship between the two cell lineages.

Hormones regulating bone and fat metabolisms include insulin and leptin, both of which are known to be related to the PPAR $\gamma$ signaling. Insulin is known to play important anabolic roles in bone (30), and deficiency of insulin signaling is associated with osteopenia both in mice and humans $(27,50-52)$. A series of reports demonstrated that leptin, a well-known anorexigenic hormone secreted by adipocytes (53), also shows antiosteogenic action centrally through the hypothalamic and sympathetic nervous systems $(11,13,31)$. In the present study, neither insulin nor leptin seemed to mediate the high bone mass in PPAR $\gamma^{+/-}$mice, since the serum levels of these hormones were, quite unexpectedly, the opposite of those causing osteogenic functions. PPAR $\gamma$ activation is known to cause insulin sensitivity, thus $P P A R \gamma^{1-}$ mice were assumed to develop insulin resistance; however, the serum insulin level was normal or somewhat decreased as previously reported $(22,29)$. This appears, at least in part, due to hypersecretion of leptin, which was also unexpected, given that the marrow adipocytes, a positive regulator of leptin expression, were decreased in $P P A R \gamma^{\dagger /}$ mice. Our previous studies clearly demonstrated that cultured primary adipocytes from $P P A R \gamma^{+/}$mice expressed and secreted increased levels of leptin as compared with those from WT $(22,29)$. In this respect, since leptin is known to have a functional PPRE whose activity is suppressed by PPAR $\gamma$ activation in adipocytes $(54,55)$, it is likely that the increased level of leptin is due to a partial release from the suppressive effect of PPAR $\gamma$ on leptin gene transcription by loss of one PPAR $\gamma$ allele.

Age-related bone loss has been suggested to be attributable to increased adipogenesis at the expense of osteoblastogenesis (7-9). Indeed, studies of SAMP6 mice, a murine model of age-related osteopenia, have established a tight association between osteopenia and enhanced adipogenesis $(10,15)$. The fact that the effects of PPAR $\gamma$ haploinsufficiency on both the increase in bone volume and the decrease in adipocytes were stronger at 52 weeks than at 8 weeks suggests the involvement of the PPAR $\gamma$ signaling in the pathophysiology of human age-related osteoporosis. In fact, our preliminary examination of the bone marrow specimen from patients with femoral neck fracture actually showed increases of both the PPAR $\gamma$ mRNA level and fat mass in older patients (data not shown) as compared with those in younger patients, although the causality between PPAR $\gamma$ level and adipogenesis remains unknown since adipocytes can be both the source and the target 
of PPAR $\gamma$. An association study between bone density and a genetic polymorphism of PPAR $\gamma$ in postmenopausal women implies the involvement of PPAR $\gamma$ in bone loss, although the functional relevance remains unclear (56). We should, however, keep in mind that there are two distinct factors that determine involutional osteoporosis: a rapid bone loss after menopause as a result of estrogen withdrawal and a gradual age-related bone loss thereafter (57). From the present study showing that PPAR $\gamma$ insufficiency did not affect bone loss by OVX, PPAR $\gamma$ may not be involved in the former stage, but may play a role in the latter. To confirm the involvement of PPAR $\gamma$ in human osteoporosis, the next task ahead of us will be to perform a genetic association study with stratified analysis by age and menopausal state, and more importantly, to use a cohort population.

We conclude herein that PPAR $\gamma$ haploinsufficiency leads to the increase of bone mass by stimulating osteoblastogenesis from bone marrow progenitors without affecting differentiated osteoblasts or osteoclast lineage cells. Based on the present and previous evidence presented, we believe that PPAR $\gamma$ may be a novel target for therapeutic intervention of osteopenic disorders, although the mechanism remains to be clarified. Appropriate functional antagonism of
PPAR $\gamma$ may provide a potentially novel approach to increasing bone formation and therefore, as a stand-alone therapy or in combination with an antiresorptive medication, may provide more efficacious prevention or treatment of osteoporosis.

\section{Acknowledgments}

We thank the hard tissue research team at Kureha Chemical Co. for technical assistance. We are grateful to Bruce M. Spiegelman for the pBabe-mPPAR $\gamma 2$-puro vector. This work was supported by Grantsin-Aid for Scientific Research from the Japanese Ministry of Education, Culture, Sports, Science, and Technology (1370303) and the ONO Medical Research Foundation.

Received for publication August 28, 2003, and accepted in revised form January 6, 2004.

Address correspondence to: Hiroshi Kawaguchi, Department of Orthopaedic Surgery, Faculty of Medicine, University of Tokyo, Hongo 7-3-1, Bunkyo-ku, Tokyo 113-8655, Japan. Phone: 8133815-5411 ext. 30473 or 33376; Fax: 81-33818-4082; E-mail: kawaguchi-ort@h.u-tokyo.ac.jp.
1. Beresford, J.N. 1989. Osteogenic stem cells and the stromal system of bone and marrow. Clin. Orthop. 240:270-280.

2. Pittenger, M.F., et al. 1999. Multilineage potential of adult human mesenchymal stem cells. Science. 284:143-147.

3. Bennett, J.H., Joyner, C.J., Triffitt, J.T., and Owen, M.E. 1991. Adipocytic cells cultured from marrow have osteogenic potential. J. Cell Sci. 99:131-139.

4. Nuttall, M.E., Patton, A.J., Olivera, D.L., Nadeau, D.P., and Gowen, M. 1998. Human trabecular bone cells are able to express both osteoblastic and adipocytic phenotype: implications for osteopenic disorders. J. Bone Miner. Res. 13:371-382.

5. Park, S.R., Oreffo, R.O., and Triffitt, J.T. 1999. Interconversion potential of cloned human marrow adipocytes in vitro. Bone. 24:549-554.

6. Beresford, J.N., Bennett, J.H., Devlin, C., Leboy, P.S., and Owen, M.E. 1992. Evidence for an inverse relationship between the differentiation of adipocytic and osteogenic cells in rat marrow stromal cell cultures. J. Cell Sci. 102:341-351.

7. Meunier, P., Aaron, J., Edouard, C., and Vignon, G. 1971. Osteoporosis and the replacement of cell populations of the marrow by adipose tissue. A quantitative study of 84 iliac bone biopsies. Clin. Orthop. 80:147-154.

8. Burkhardt, R., et al. 1987. Changes in trabecular bone, hematopoiesis and bone marrow vessels in aplastic anemia, primary osteoporosis, and old age: a comparative histomorphometric study. Bone. 8:157-164.

9. Rozman, C., et al. 1989. Age-related variations of fat tissue fraction in normal human bone marrow depend both on size and number of adipocytes: a stereological study. Exp. Hematol. 17:34-37.

10. Jilka, R.L., Weinstein, R.S., Takahashi, K., Parfitt, A.M., and Manolagas, S.C. 1996. Linkage of decreased bone mass with impaired osteoblastogenesis in a murine model of accelerated senescence. J. Clin. Invest. 97:1732-1740.

11. Ducy, P., et al. 2000. Leptin inhibits bone formation through a hypothalamic relay: a central control of bone mass. Cell. 100:197-207.

12. Sabatakos, G., et al. 2000. Overexpression of DeltaFosB transcription factor(s) increases bone formation and inhibits adipogenesis. Nat. Med. 6:985-990.

13. Takeda, S., et al. 2002. Leptin regulates bone formation via the sympathetic nervous system. Cell. 111:305-317.
14. Takeuchi, Y., et al. 2002. Interleukin-11 as a stimulatory factor for bone formation prevents bone loss with advancing age in mice. J. Biol. Chem. 277:49011-49018.

15. Kodama, Y., et al. 1998. Reduced expression of interleukin-11 in bone marrow stromal cells of senescence-accelerated mice (SAMP6): relationship to osteopenia with enhanced adipogenesis. J. Bone Miner. Res. 13:1370-1377.

16. Rosen, E.D., Walkey, C.J., Puigserver, P., and Spiegelman, B.M. 2000. Transcriptional regulation of adipogenesis. Genes Dev. 14:1293-1307.

17. Rosen, E.D., and Spiegelman, B.M. 2001. PPAR $\gamma$ : a nuclear regulator of metabolism, differentiation, and cell growth. J. Biol. Chem. 12:37731-37734.

18. Kersten, S., Desvergne, B., and Wahli, W. 2000. Roles of PPARs in health and disease. Nature. 405:421-424.

19. Mangelsdorf, D.J., and Evans, R.M. 1995. The RXR heterodimers and orphan receptors. Cell. 83:841-850.

20. Tontonoz, P., Hu, E., and Spiegelman, B.M. 1994 Stimulation of adipogenesis in fibroblasts by PPAR $\gamma 2$, a lipid-activated transcription factor. Cell. 79:1147-1156.

21. Barak, Y., et al. 1999. PPAR $\gamma$ is required for placental, cardiac, and adipose tissue development. Mol. Cell. 4:585-595.

22. Kubota, N., et al. 1999. PPAR $\gamma$ mediates high-fat diet-induced adipocyte hypertrophy and insulin resistance. Mol. Cell. 4:597-609.

23. Rosen, E.D., et al. 1999. PPAR $\gamma$ is required for the differentiation of adipose tissue in vivo and in vitro. Mol. Cell. 4:611-617.

24. Kadowaki, T. 2000. Insights into insulin resistance and type 2 diabetes from knockout mouse models. J. Clin. Invest. 106:459-465.

25. Bradley, A. 1987. Production and analysis of chimaeric mice. In Teratocarcinomas and embryonic stem cells. E.J. Robertson, editor. IRL Press. Oxford, United Kingdom. 113-151.

26. Keller, G.M. 1995. In vitro differentiation of embryonic stem cells. Curr. Opin. Cell Biol. 7:862-869.

27. Akune, T., et al. 2002. Insulin receptor substrate-2 maintains predominance of anabolic function over catabolic function of osteoblasts. J. Cell Biol. 159:147-156.

28. Kobayashi, K., et al. 2000. Tumor necrosis factor $\alpha$ stimulates osteoclast differentiation by a mechanism independent of the ODF/RANKL-RANK interaction. J. Exp. Med. 191:275-286.

29. Yamauchi, T., et al. 2001. The mechanisms by which both heterozygous peroxisome proliferator-activated receptor $\gamma$ (PPAR $\gamma$ ) deficiency and PPARgamma agonist improve insulin resistance. J. Biol. Chem. 276:41245-41254.

30. Thomas, D.M., Hards, D.K., Rogers, S.D., Ng, K.W., and Best, J.D. 1997. Insulin and bone, clinical and scientific view. Endocrinology and Metabolism. 4:5-17.

31. Takeda, S., and Karsenty, G. 2001. Central control of bone formation. J. Bone Miner. Metab. 19:195-198.

32. Tanaka, T., Yoshida, N., Kishimoto, T., and Akira, S. 1997. Defective adipocyte differentiation in mice lacking the $\mathrm{C} / \mathrm{EBP} \beta$ and/or $\mathrm{C} / \mathrm{EBP} \delta$ gene. $E M B O J$. 16:7432-7443

33. Wu, Z., et al. 1999. Cross-regulation of C/EBP $\alpha$ and PPAR $\gamma$ controls the transcriptional pathway of adipogenesis and insulin sensitivity. Mol. Cell. 3:151-158.

34. Karsenty, G. 2001. Minireview: transcriptional control of osteoblast differentiation. Endocrinology. 142:2731-2733.

35. Nakashima, K., et al. 2002. The novel zinc finger-containing transcription factor osterix is required for osteoblast differentiation and bone formation. Cell. 108:17-29.

36. Patel, M.S., and Karsenty, G. 2002. Regulation of bone formation and vision by LRP5. N. Engl. J. Med. 346:1572-1574.

37. Suda, T., et al. 1999. Modulation of osteoclast differentiation and function by the new members of the tumor necrosis factor receptor and ligand families. Endocr. Rev. 20:345-357.

38. Lecka-Czernik, B., et al. 1999. Inhibition of Osf2/Cbfa1 expression and terminal osteoblast differentiation by PPAR $\gamma 2$. J. Cell. Biochem. 74:357-371.

39. Ricote, M., Li, A.C., Willson, T.M., Kelly, C.J., and Glass, C.K. 1998. The peroxisome proliferator-activated receptor- $\gamma$ is a negative regulator of macrophage activation. Nature. 391:79-82.

40. Tolon, R.M., Castillo, A.I., and Aranda, A. 1998. Activation of the prolactin gene by peroxisome proliferator-activated receptor- $\alpha$ appears to be DNA binding-independent. J. Biol. Chem. 273:26652-26661.

41. Benson, S., Wu, J., Padmanabhan, S., Kurtz, T.W., and Pershadsingh, H.A. 2000. Peroxisome proliferatoractivated receptor (PPAR) $\gamma$ expression in human vascular smooth muscle cells: inhibition of growth, migration, and c-fos expression by the peroxisome proliferator-activated receptor (PPAR)- $\gamma$ activator troglitazone. Am. J. Hypertens. 13:74-82.

42. Alliston, T., Choy, L., Ducy, P., Karsenty, G., and 
Derynck, R. 2001. TGF- $\beta$-induced repression of CBFA 1 by Smad 3 decreases cbfa 1 and osteocalcin expression and inhibits osteoblast differentiation. EMBO J. 20:2254-2272.

43. Borton, A.J., Frederick, J.P., Datto, M.B., Wang, X.F., and Weinstein, R.S. 2001. The loss of Smad3 results in a lower rate of bone formation and osteopenia through dysregulation of osteoblast differentiation and apoptosis. J. Bone Miner. Res. 16:1754-1764.

44. Fu, M., et al. 2001. Peroxisome proliferator-activated receptor $\gamma$ inhibits transforming growth factor betainduced connective tissue growth factor expression in human aortic smooth muscle cells by interfering with Smad3. J. Biol. Chem. 276:45888-45894.

45. Ross, S.E., et al. 2000. Inhibition of adipogenesis by Wnt signaling. Science. 289:950-953.

46. Bennett, C.N., et al. 2002. Regulation of Wnt signaling during adipogenesis. J. Biol. Chem. 277:30998-31004.

47. Bain, G., Muller, T., Wang, X., and Papkoff, J. 2003.
Activated $\beta$-catenin induces osteoblast differentiation of C3H10T1/2 cells and participates in BMP2 mediated signal transduction. Biochem. Biophys. Res. Commun. 301:84-91.

48. Smith, E., Coetzee, G.A., and Frenkel, B. 2002. Glucocorticoids inhibit cell cycle progression in differentiating osteoblasts via glycogen synthase kinase- $3 \beta$. J. Biol. Chem. 277:18191-18197.

49. Garcia, T., et al. 2002. Behavior of osteoblast, adipocyte, and myoblast markers in genome-wide expression analysis of mouse calvaria primary osteoblasts in vitro. Bone. 31:205-211.

50. Krakauer, J.C., McKenna, M.J., Rao, D.S., and Whitehouse, F.W. 1997. Bone mineral density in diabetes. Diabetes Care. 20:1339-1340.

51. Piepkorn, B., et al. 1997. Bone mineral density and bone metabolism in diabetes mellitus. Horm. Metab. Res. 29:584-591.

52. Ogata, N., et al. 2000. Insulin receptor substrate-1 in osteoblast is indispensable for maintaining bone turnover. J. Clin. Invest. 105:935-943.

53. Elmquist, J.K., Elias, C.F., and Saper, C.B. 1999. From lesions to leptin: hypothalamic control of food intake and body weight. Neuron. 22:221-232.

54. Kallen, C.B., and Lazar, M.A. 1996. Antidiabetic thiazolidinediones inhibit leptin (ob) gene expression in 3T3-L1 adipocytes. Proc. Natl. Acad. Sci. U. S. A. 93:5793-5796.

55. Hollenberg, A.N., et al. 1997. Functional antagonism between CCAAT/enhancer binding protein- $\alpha$ and peroxisome proliferator-activated receptor- $\gamma$ on the leptin promoter. J. Biol. Chem. 272:5283-5290.

56. Ogawa, S., et al. 1999. Association of bone mineral density with a polymorphism of the peroxisome proliferator-activated receptor $\gamma$ gene: PPAR $\gamma$ expression in osteoblasts. Biochem. Biophys. Res. Commun. 260:122-126.

57. Nguyen, T.V., Blangero, J., and Eisman, J.A. 2000. Genetic epidemiological approaches to the search for osteoporosis genes. J. Bone Miner. Res. 15:392-401. 